\title{
ALFABETIZAÇÃO DE JOVENS E ADULTOS: POLÍTICA PÚBLICA E MOVIMENTO POPULAR
}

\author{
Alda Maria Borges Cunha* \\ Maria Emilia de C. Rodrigues* \\ Maria Margarida Machado**
}

\begin{abstract}
RESUMO: O presente texto versa sobre a alfabetização de jovens e adultos realizada pelo Projeto AJA-Expansão, da Secretaria Municipal de Goiânia (SME), desenvolvido em parceria com a sociedade civil, universidades e outras instituições. Esse projeto configura-se na concretização de uma bandeira de luta contra o analfabetismo em Goiânia, fazendo parte de uma política pública municipal de combate emergencial e estrutural às situações de exclusão social. $\mathrm{O}$ texto apresenta as origens e estrutura do Projeto AJA-Expansão e o papel do Estado - como implementador de políticas públicas - e da sociedade civil, configurando-se em um movimento de educação popular.
\end{abstract}

Palavras-chave: Alfabetização de jovens e adultos. Política pública de educação. Parceria entre Estado e sociedade civil.

\section{YOUTH AND ADULT EDUCATION: PUBLIC POLICIES AND POPULAR MOVEMENT}

ABSTRACT: This text explores a literacy program directed to youth and adults, the AJA-Outreach Project of the Municipal Secretariat of Goiânia, developed in partnership with the civil society, universities and other institutions. Part of a municipal public policy to overcome situations of social exclusion, at both emer-

* Doutora Honoris Causa e professora do Departamento de Educação da Universidade Católica de Goiás (UCG).E-mail: getg@ucg.br

** Doutoranda em Educação e professora da Faculdade de Educação da Universidade Federal de Goiás (UFG). E-mail: me.castro@terra.com.br

*** Doutora em Educação e professora da Faculdade de Educação da UFG.

E-mail:mmm2@terra.com.br 
gency and structural levels, it became a front to fight illiteracy in Goiânia. In addition to presenting the role of the State, which rules public policies, and of civil society, the text retraces the origins and structure of the AJA-Outreach Project, showing how it evolved to become a movement for popular education.

Key words: Youth and adult literacy. Public educational policies. State and civil society partnership.

\section{Introdução}

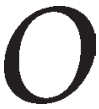

Projeto AJA-Expansão, da Secretaria Municipal de Goiânia (SME), criado em 2001 e desenvolvido em parceria com a sociedade civil, universidades e outras instituiçōes, constitui-se em uma oportunidade de iniciar o processo de alfabetização de adolescentes, jovens e adultos, com vistas a garantir-lhes o acesso ao ensino fundamental. Trata-se da concretização de uma bandeira de luta na defesa da educação como direito de todos, a iniciar-se pelo processo de alfabetização em Goiânia, fazendo parte de uma política pública municipal integrada de combate emergencial e estrutural às situações de exclusão social.

Esse Projeto configura-se em um movimento popular de alfabetização constituído a partir de uma resposta da sociedade civil, ONGs, universidades e instituiçōes - sensibilizadas com o índice de analfabetismo apontado pelo Censo de 2000 do IBGE, em Goiânia, de 42.303 pessoas - ao chamado da SME deste município, como indutora de políticas públicas, para o enfrentamento deste desafio.

\section{As origens do Projeto AJA-Expansão}

Num esforço coletivo, pautado nos princípios da Educação Popular, e contando com o apoio administrativo, pedagógico e financeiro da SME, buscamos construir um projeto de alfabetização de jovens e adultos, assentado na história dos movimentos populares vividos em Goiás, e mais especificamente em Goiânia, desde os anos de 1960, com os Círculos de Cultura, fundamentados nas idéias de Paulo Freire, muito presentes à época.

No início da década de 1960, Goiás, a exemplo de outros estados, acumulou significativa história na educação popular numa pers- 
pectiva emancipatória, empreendida pelos movimentos populares ligados à cultura e à educação de adultos, com experiências como o Movimento de Cultura Popular (MCP), Centro Popular de Cultura (CPC) e Movimento de Educação de Base (MEB). História pouco registrada, por fazer parte de memórias marginais: quer seja pelas circunstâncias históricas da ditadura militar que provocaram a interrupção ou reorganização desses movimentos; pela ausência de registros e/ou apagamento destes, restringindo a pessoas, individualmente, o conhecimento de fatos importantes, gerando um vácuo no nosso passado cultural; quer seja pelo espaço marginal que a educação de jovens e adultos ocupa no processo educacional. O MEB foi o único movimento desse período que se manteve em Goiás pós-golpe de 1964: encerrado em 1966 com a ditadura militar, retomou suas atividades de 1997 a 2001, quando suas turmas foram incorporadas ao Projeto AJA-Expansão.

Desde a década de 1970, a Rede Municipal de Educação de Goiânia já contava com o ensino supletivo para atender jovens e adultos. A partir do final da década de 1980, a Secretaria opta pela implantação do ensino noturno para a educação de jovens e adultos (EJA). Contudo, esta modalidade só passou a ser tratada com especificidade a partir de 1992, quando da criação da Equipe de Ensino Noturno. Vale ressaltar que a EJA em Goiânia, já neste período, não se restringia à esfera da rede oficial de ensino.

A exemplo disso é que, em 1991, em paralelo ao sistema de ensino noturno de Goiânia, professores e alunos estagiários do curso de Pedagogia da Faculdade de Educação da Universidade Federal de Goiás (UFG), otimistas frente aos desafios de uma educação popular e da discussão pela redemocratização, participaram da elaboração do Projeto Intenção de Estudos, que atendia adolescentes e jovens analfabetos, na faixa etária de 11 a 17 anos. O projeto foi aprovado em agosto de 1992 e, devido à dificuldade financeira - advinda da demora na liberação dos recursos e da conseqüente defasagem, decorrida pelo processo inflacionário acentuado - para sua implementação, a Universidade buscou a parceria da SME, que liberou duas professoras para atuarem no Projeto.

Em 1993, assumiu a prefeitura de Goiânia o Partido dos Trabalhadores (PT), que empreendeu um projeto de educação que defendia: a escola pública popular gratuita, democrática e de qualidade; os prin- 
Alfabetização de jovens e adultos: política pública e movimento popular

cípios de garantia de acesso e permanência das classes populares na escola. No seio destas defesas nasceram propostas específicas de experiências para a EJA, tais como: a proposta de erradicação do analfabetismo por meio do programa de Educação Popular, com os Círculos de Cultura, que permaneceram em ação até 1996; a criação do setor de EJA na SME e a implantação da Experiência Pedagógica de $1^{\text {a }}$ a $4^{\mathrm{a}}$ Séries do Ensino Fundamental para Adolescentes, Jovens e Adultos, mais conhecida como Projeto AJA.

Os Círculos de Cultura, aos moldes dos anos de 1960, foi um movimento de alfabetização popular implementado em Goiânia, no período de agosto de 1993 a dezembro de 1996, que surgiu quando a SME firmou convênio com a Confederação Nacional dos Bispos do Brasil/Movimento de Educação de Base (СNBB/MEB), com o objetivo de buscar os alunos que não estavam procurando as escolas e criar neles o desejo de estudar, mobilizando-os por meio do processo inicial de alfabetização e elevação da auto-estima. No início foram abertos trinta (30) Círculos de Cultura, sendo 14 vinculados a entidades religiosas, 6 a associações de moradores, 5 a sindicatos e 5 a empresas públicas. Eles funcionavam em três dias semanais alternados - segunda, quarta e sexta -, num período mínimo de duas horas em cada encontro. As/os monitoras/es eram educadoras/es populares indicados pelos parceiros. A formação das/os monitoras/es para atuar nos Círculos de Cultura era realizada pela SME, em parceria com o MEB, sendo que, nas trocas de experiências, tinha o/a educador/a observador/a que auxiliava na formação de ambos.

O Projeto AJA retomava características da educação básica construída pelas camadas populares na década de 1960, resgatando o conteúdo político das propostas ali desenvolvidas, com vistas a incorporá-las no seio das redes municipais de ensino. Objetivando trabalhar com adolescentes, jovens e adultos excluídos da escola por falta de condições, repetências sucessivas, inadequação à metodologia infantilizada ou por indisciplina, este projeto foi proposto pela SME (1996, p. 5) como: “(...) uma experiência pedagógica que vem tentando implementar um novo jeito de ser da escola: horários e freqüências flexíveis, conteúdos e metodologias diferenciados, atividades culturais com todas as turmas, encontros semanais com professores para estudo e avaliação".

Ele possuía, como princípios teórico-filosóficos norteadores de sua proposta pedagógica: 
(...) O conceito de Cidadania, (...) concebido como igualdade política, econômica, jurídica, social e cultural, compreendida como processo de construção social forjado no interior da prática social e política dos movimentos populares. Implicando a conquista do direito ao atendimento de todas as necessidades básicas da pessoa humana.

O conceito de Identidade, (...) definido (...) como processo em que os sujeitos são autores de sua própria identidade, no convívio social e na construção da sociedade em que vivem.

O conceito de Aprendizagem, conotado pela prática de uma construção conjunta de conhecimento, sendo professores e alunos sujeitos da aprendizagem.

A concepção de linguagem (...) baseada na perspectiva interacionista da linguagem, conceituada como processo de interação verbal, social e política. A concepção da leitura e escrita se configura como construção coletiva superando a concepção de decodificação mecânica de sons e de transcrição gráfica de palavras, que tem norteado o processo de 'alfabetização'. Neste sentido, o que se propõe é uma leitura e escrita que abram aos educandos a diversidade do conhecimento, lhes possibilite ler criticamente sua realidade e participar do processo de transformação de si e de sua sociedade. (SME, 1993, p. 8)

A partir de 1997, os princípios e avanços construídos e vivenciados pelo Projeto AJA foram sendo incorporados às demais turmas de $1^{\mathrm{a}}$ a $4^{\mathrm{a}} \mathrm{e}$, posteriormente, de $5^{\mathrm{a}}$ a $8^{\mathrm{a}}$ séries do ensino fundamental para adolescentes jovens e adultos, na SME de Goiânia, não ficando restritos ao projeto experimental. Isto se intensificou com a plataforma de governo popular do PT, na gestão 2001-2004, onde estava posta a necessidade de resgate da dívida social para com o povo excluído e marginalizado, sendo um dos enfoques o processo de educação extensivo a todos, especialmente aos jovens e adultos que não tiveram acesso ou foram excluídos do processo educativo escolar.

Em função da assertividade, adequação e aceitação pela sociedade goianiense, o Projeto AJA desdobrou-se em uma articulação com os movimentos populares, originando o Projeto AJA-Expansão, desenvolvido em parceria com os movimentos sociais. Nesse sentido, acreditando em uma sociedade mais justa e igualitária, a SME vem, desde 2001, unificando esforços com a sociedade civil e estabelecendo parcerias com empresas, sindicatos, igrejas, associações de bairros, associações de idosos e outras instituições, somando, em 2005, 150 parceiros para juntos implementarem e ampliarem o Projeto AJA-Expansão. Projeto este 
que compõe uma grande rede alfabetizadora no Brasil, o Movimento de Alfabetização de Jovens e Adultos (MOVA-Brasil). Desde 2003, este projeto conta também com a parceria com o governo federal, integrando o Projeto AJA-Expansão ao Programa Brasil Alfabetizado e realizando um grande movimento nacional pela alfabetização de jovens e adultos.

Enquanto MOVA ${ }^{1}$ de Goiânia, o Projeto AJA-Expansão tem suas raízes nos movimentos populares, grupos e organizações que, inspirados no legado de Paulo Freire, vêm atuando há longa data no campo da alfabetização e da educação básica de jovens e adultos, articulando-se nacionalmente, discutindo e propondo políticas públicas para essa modalidade. O Projeto AJA-Expansão buscou na estrutura e princípios dos Círculos de Cultura - tanto da década de 1960 dos movimentos populares de âmbito nacional, quanto da experiência de 1993 em Goiânia sua forma de organização, enriquecendo com as vivências da organização institucional do Projeto AJA de Goiânia.

Os princípios da Educação Popular articulam-se a esses princípios básicos do Projeto AJA-Expansão e são norteadores do seu conteúdo, das metodologias, das relaçôes interpessoais, do processo de avaliação, entre outros aspectos.

Política pública de educação de jovens e adultos: o papel do Estado e da sociedade civil

Segundo Pedro Pontual (2003, p. 5), é de fundamental importância que se reflita sobre o

(...) papel do Estado e da sociedade civil, pois a prática de parceria entre Estado e sociedade civil numa perspectiva substantivamente democrática requer a união de ambas as vontades políticas e ao mesmo tempo um profundo respeito pela autonomia dos atores e uma clara definição de responsabilidades.

Alguns elementos acerca do papel da sociedade civil e dos sujeitos partícipes do Projeto AJA-Expansão, que corroboram com as reflexões de Pontual (2003), merecem ser destacados. Primeiramente, a dimensão de movimento presente na proposta do Projeto, como movimento de alfabetização de jovens e adultos que tem nos atores da sociedade civil os principais responsáveis pela sua realização/vitalização. É preciso recuperar a 
idéia de que ele é um movimento social que, em parceria com a SME de Goiânia, toma a questão da alfabetização e da pós-alfabetização dos jovens e adultos como uma tarefa inicial na luta pelo direito à educação ao longo de toda a vida. Esta dimensão coloca o desafio para os atores da sociedade civil que ingressam no Projeto AJA-Expansão (educadoras/ es e educandas/os) de se organizarem, a partir da prática da sala de aula e para além da mesma, como movimento social que luta pelo direito à educação, que sabemos indissociável do conjunto dos direitos econômicos, sociais, culturais e ambientais.

Esta compreensão do papel do Projeto AJA-Expansão vincula-o ao campo das práticas de construção de uma cidadania ativa e, ao mesmo tempo, coloca o referencial da Educação Popular como aquele mais coerente para a consecução de seus objetivos. Como nos diz o lema do Projeto: "Ler o mundo, escrever a vida". E, no dizer de Carlos Brandão (1980, p. 129), "O horizonte da educação popular não é o homem educado, é o homem convertido em classe. É o homem libertado".

Os parceiros do Projeto AJA-Expansão, como atores sociais, devem demandar e propor ao Estado açōes que reconheçam, entre outros aspectos, a diversidade de gênero, étnica e geracional; os aspectos ligados às especificidades dos sujeitos da EJA, com sua relação direta com o mundo do trabalho, com as questóes prementes da sobrevivência e, para isto, com a geração de renda, com o enfrentamento cotidiano numa sociedade do conhecimento, que passa pela inclusão digital, mas nela não se esgota.

Outro elemento importante é a autonomia, como movimento, para que sua organização não fique refém dos processos eleitorais. Para que isto de fato ocorra, os parceiros do Projeto precisam buscar uma participação ativa nos processos de gestão das políticas públicas em geral, como no orçamento participativo, nos fóruns de EJA e de juventude, e em outros espaços que vão se constituindo na cidade. E, ainda,

Como movimento social cabe assim aos sujeitos partícipes do [Projeto AJAExpansão] (...) (educadores, educandos, coordenadores, gestores) combinarem a necessária competência político-pedagógica da sala de aula com a ação igualmente competente como militantes na luta pelo direito à educação ao longo de toda a vida dos jovens e adultos. Por isso, Paulo Freire, (...) afirma que "a educação de adultos virando educação popular se tornou mais abrangente": educadores e grupos populares descobriram que 
educação popular é sobretudo o processo permanente de refletir a militância; refletir, portanto, a sua capacidade de mobilizar em direção a objetivos próprios. A prática educativa, reconhecendo-se como prática política, se recusa a deixar-se aprisionar na estreiteza burocrática de procedimentos escolarizantes. Lidando com o processo de conhecer, a prática educativa é tão interessada em possibilitar o ensino de conteúdos às pessoas quanto em sua conscientização. (Pontual, 2003, p. 6-7).

Diante destes elementos, o Projeto AJA-Expansão tem enfrentado um conjunto enorme de desafios. Entre eles, a articulação junto às comunidades, fomentando a construção da cultura de alfabetização, que levou a diversas iniciativas para localizar o público específico para as turmas, como a utilização dos dados do cadastro do Programa Saúde da Família (PSF); os dados da listagem do Tribunal Regional Eleitoral e uma mobilização no segundo turno das eleiçôes para o mapeamento dos eleitores não-alfabetizados. Estes dados colaboraram para a definição das áreas de maior concentração de possíveis educandos e para a mobilização e organização das turmas, formando os grupos de alfabetização o mais próximo possível da demanda localizada.

Outro desafio trata-se do compromisso dos parceiros com a cessão do espaço físico e manutenção do mesmo, para o funcionamento das turmas, bem como a indicação dos alfabetizadores para o projeto. Cabendo, neste caso, ao poder público, numa ação conjunta às Universidades Federal e Católica de Goiás (UFG e UCG), a formação inicial e continuada das/os alfabetizadoras/es e o acompanhamento a estas/es educadoras/es populares e às/aos apoiadoras/es pedagógicas/os, articulando o Projeto AJA-Expansão com outras experiências co-irmãs para planejar apoio futuro.

Um importante compromisso do Projeto AJA-Expansão é com a construção de alternativas para a garantia de sua continuidade, especialmente em caso de uma alternância de governo. Esta preocupação se faz presente, inclusive, na qualificação e na busca de crescimento da oferta, evitando, com isso, que os educandos do Projeto não consigam a continuidade da escolarização e/ou rejeitem a educação de adolescentes, jovens e adultos (EAJA). Instrumento importante para a garantia desta continuidade tem sido a busca da implementação do Plano Municipal de Educação, no que se refere à EJA, e à própria organização autônoma das/os alfabetizadoras/es e parceiros, que passam a se organizar em busca da garantia da educação como direito. 
É ainda desafio, mas também já conquista, a participação de educandas/os, educadoras/es, coordenadoras/es e gestoras/es em encontros de educação locais, regionais, estaduais, nacionais e internacionais; sistematizando e divulgando a experiência do Projeto, contando com apoio, inclusive financeiro, da SME. Todos estes elementos contribuem para a construçáo de uma pedagogia própria, alicerçada em Paulo Freire e no paradigma da Educação Popular.

A perspectiva do Projeto é da luta pelo direito à educação como parte de uma luta maior, a luta pela universalização do conjunto dos direitos econômicos, sociais, culturais e ambientais a todos - homens e mulheres, independente da idade, cor, raça -, capaz de assegurar um Brasil alfabetizado, mas também capaz de assegurar justiça, eqüidade, substantividade democrática para todos seus cidadãos e cidadâs. Pois, se é verdade que a educação sozinha não é capaz de construir cidadania, de transformar a realidade que vivemos, é também verdade que sem ela a cidadania ativa não se realiza, os seres humanos não se constituem como tal e não se percebe que o mundo é feito pelos homens e por eles pode ser transformado.

Quanto ao papel do Municipio, Estado ou Uniāo, cabe destacar a importância do poder público para fomentar, criar e implementar uma política pública que garanta o direito à alfabetização/educação para todos; chamar a sociedade civil para compartilhar da realização dos movimentos de alfabetização; apoiar as experiências de alfabetização/educação popular existentes. O Projeto AJA-Expansão, como movimento de alfabetização com identidade própria, faz parte do plano de educação e do programa de governo, mantendo-se o respeito à identidade do Projeto que, como movimento educacional, como ação política e cultural, se afirma e se expande.

Nesse sentido, o conceito de parceria necessita tomar corpo e fortalecer o diálogo entre o poder público e a sociedade civil, onde a alfabetização de pessoas jovens e adultas passa a ser vista como uma estratégia não só educativa, mas também de desenvolvimento econômico solidário e popular. Tudo isso só se realiza com a garantia de financiamento e gerenciamento do Projeto AJA-Expansão, inclusive quando se trata de elementos essenciais para a permanência das/os alfabetizandas/ os, tais como a alimentação (merenda), o material de apoio didático e a formação continuada em rede para todos os participantes. 
Outro aspecto importante nesta relação de parceria entre o poder público e o movimento social é a garantia de uma rede de formação permanente do Projeto AJA-Expansão, abrangendo todos os protagonistas educadores, assessoria, apoiadores, entidades, educandos e coordenação, em espaços sistemáticos de reflexão estadual, regional e local, planejados coletivamente ao longo da práxis. Isso fortalece a busca de garantia de continuidade do Projeto AJA-Expansão, especialmente em caso de uma alternância de governo; prepara os mecanismos legais para futura sustentação do Projeto. Por fim, possibilita a compreensão do Projeto como parte da política educacional da Secretaria de Educação, participando da totalidade do processo de construção da educação de jovens e adultos (EJA ${ }^{2}$ ), ou seja, evita o isolamento e a disputa política interna na Secretaria $\mathrm{Mu}-$ nicipal de Educação entre o Projeto AJA-Expansão e a EAJA, deixando claro que o Projeto é parte integrante desta, configurando-se em uma das formas de proporcionar o acesso inicial à escolarização dos jovens e adultos atendidos pela SME.

Para exemplificar as possibilidades várias que resultam desta ação de parceria do poder público com o movimento social, serão destacados abaixo dois resultados importantes da ação do Projeto AJA-Expansão: a diferenciação da EJA na SME, ao receber os alunos egressos do Programa, e a política de formação das/os alfabetizadoras/es realizada pelos parceiros, as universidades.

\section{O Projeto AJA-Expansão e sua relação com a EJA}

Nesses cinco anos foram atendidos dez mil alunos, sendo que, ao final de cada etapa, o Projeto AJA-Expansão promove uma grande festa para entrega de certificados daqueles que desejam ir para a escola, dar seqüência aos estudos. Esta entrega de certificados tem atingido uma média de 500 alunos/ano, o que representa uma entrada aproximada de $30 \%$ dos alunos, que passam pela alfabetização inicial, no primeiro segmento do ensino fundamental.

Para receber o aluno que vem do Projeto AJA-Expansão, a rede municipal mantém duas formas de atuação: o Ensino Fundamental para Adolescentes, Jovens e Adultos (EAJA) e o AJA-Extensão. Este último trata-se de um curso modulado presencial, que corresponde ao primeiro segmento do ensino fundamental, para atender aqueles que não pude- 
ram dar continuidade ao processo de escolarização no ensino regular da EAJA. Ele é assumido pelo professor da rede municipal, podendo funcionar em escolas, locais de trabalho ou espaços comunitários, com três horas diárias de aula, como extensão de uma escola da Rede Municipal de Educação. O horário de funcionamento das turmas também é flexível, podendo ser organizadas turmas pela manhã, tarde e noite, conforme o interesse e as necessidades dos alunos. Esta forma de atendimento constitui-se em uma alternativa de escolarização de jovens e adultos, com aprovação do Conselho Municipal de Educação (CME) e uma avaliação positiva nestes dez anos. Muitas turmas do Projeto AJA-Expansão são atendidas em sua continuidade, por meio do AJA-Extensão, especialmente em associações de idosos e empresas (como a Companhia Municipal de Urbanização de Goiânia, COMURG, e a Companhia de Obras e Habitação, СОмOB, etc.), que cedem, além do espaço físico, parte da carga horária de trabalho dos trabalhadores para a efetivação do processo de escolarização dos mesmos.

A EAJA atende de $1^{\mathrm{a}}$ a $8^{\mathrm{a}}$ séries do ensino fundamental, organizada através de um projeto aprovado pelo CME: de $1^{\mathrm{a}}$ a $4^{\mathrm{a}}$ séries, com a carga horária anual de 600 (seiscentas) horas presenciais e 200 (duzentas) horas complementares, perfaz três horas diárias de aulas e duzentos dias letivos. E de $5^{\mathrm{a}}$ a $8^{\mathrm{a}}$ séries, com a carga horária de 700 (setecentas) horas presenciais e 100 (cem) horas complementares, perfaz três horas e meia de aula/dia. Há ainda uma forma de organização alternativa da EAJA, de $5^{\mathrm{a}}$ a $8^{\mathrm{a}}$ séries, em 7 (sete) escolas, para atendimento da escolarização de jovens e adultos no diurno, como extensão de uma escola, podendo funcionar na própria unidade de ensino ou em outros espaços. Esta modalidade congrega, anualmente, duas séries em uma, no trabalho empreendido, podendo o aluno avançar de uma para outra série a qualquer momento, desde que tenha condições para tal.

\section{Os educadores do Projeto: quem são e como são formados}

As/os professoras/es que atuam como alfabetizadoras/es no Projeto AJA-Expansão são denominados de educadoras/es populares. Elas/es podem ser graduadas/os ou graduandas/os em Pedagogia ou em outros cursos de licenciatura; pessoas com formação em curso de magistério de nível médio ou outros, que tenham experiência comprovada em alfabetização (EJA) e/ou de participação em movimentos populares. 
Diferentemente de outras experiências em classes de alfabetização de jovens e adultos no país, o nível de escolaridade das/os educadoras/es populares/alfabetizadoras/es do Projeto AJA-Expansão é considerável, uma vez que a maioria possui o ensino médio ou superior, embora isso não represente preparação específica para atuar na EJA.

As/os educadoras/es populares atuam como motivadoras/es no processo inicial de escolarização e são, preferencialmente, pessoas da própria comunidade e indicados pelos parceiros (universidades, igrejas, associaçōes de moradores, ONGs, empresas e sindicatos). A carga horária semanal do/a educador/a no projeto é de doze horas de atividades, sendo dez horas de trabalho efetivo com as/os alunas/os, com duas horas e trinta minutos de aula diária (de segunda a quinta-feira) e duas horas de formação contínua na sexta-feira.

Trata-se de um/a educador/a que deva ser comprometido/a política e eticamente com as classes populares, voltando sua atenção não apenas para a prática pedagógica em si, mas incluindo nela as condições sócio-histórico-político-econômicas nas quais sua prática ocorre, trazendo da realidade questóes sociais concretas relativas ao grupo com o qual trabalha. Ele necessita ser alguém que, num processo dialógico, apóia, sustenta e caminha com seus pares, aprendendo e ensinando, uns aos outros, numa relação ativa de vinculaçôes recíprocas, onde há troca e partilha de saberes.

Pensar a formação de professores - em especial das/os educadoras/es populares alfabetizadoras/es, sujeitos co-participantes do ato de ler e escrever - representa localizar as várias instâncias onde ela tem sido empreendida. Uma delas é a universidade, que tem desenvolvido pesquisas e estudos sobre a alfabetização/educação de jovens e adultos nos espaços do ensino, da pesquisa e da extensão, fornecendo subsídios para ações e projetos de alfabetização/educação de jovens e adultos. Essa formação, como um processo permanente de constituição de professores e alfabetizandos leitores e escritores, é que se tem buscado na parceria empreendida entre a Universidade Federal de Goiás (UFG), a Universidade Católica de Goiás (UCG) e a SME de Goiânia, para a formação dos educadoras/es populares alfabetizadoras/es do Projeto AJA-Expansão.

Como o Projeto atua com educadoras/es populares, que podem ser graduadas/os ou graduandas/os, pessoas com curso de magistério de nível médio, com experiência ou não com o trabalho de educação de 
jovens e adultos (EJA) e com movimentos populares, a formação destes educadores é uma tarefa bastante complexa e que não se esgota, como já foi dito, em cursos fragmentados e de caráter eventual, mas deve ser entendida como um processo permanente, que perpassa os encontros iniciais de formação de educadoras/es populares, a formação continuada semanal, os momentos de visitas às turmas de alfabetização, os encontros anuais, regionais e nacionais na área de alfabetização (EJA).

Trata-se, portanto, de uma formação que não concentra a carga horária em um único curso inicial, mas é empreendida com encontros iniciais de formação e outros encontros semanais para análise e reflexão sobre os pressupostos teórico-práticos, que sustentam o processo educativo. $\mathrm{O}$ processo de formação é visto como um momento de produção do conhecimento que se origina de questôes postas pela prática. São, portanto, essas questões constituídas no processo educativo que buscamos responder na formação continuada de educadoras/es populares.

O encontro inicial de formação perfaz 30 horas e configura-se em um momento de sensibilização para o trabalho voltado para a alfabetização/educação de adolescentes, jovens e adultos, sendo pensado no sentido de refletir sobre quem é o aluno e o educador da EAJA, que educação é essa que almejamos empreender, para que tipo de sociedade vivemos e a quem queremos formar, além de responder a uma série de perguntas que se colocam aos educadores que estão prestes a iniciar o trabalho educativo, especialmente considerando a realidade desses alunos.

A formação inicial é ministrada por professoras da UFG, UCG e coordenadoras/es do Projeto AJA-Expansão. Estas professoras das universidades acompanham o projeto desde a sua criação, sendo elas especialistas, mestras e doutoras, com formação em educação e com estudos, pesquisas e práticas em EJA e educação popular. As/os coordenadoras/es, em sua maioria, são graduadas/os ou graduandas/os, ou, ainda, educadoras/es populares com experiências em alfabetização de jovens e adultos advindos de movimentos anteriormente vivenciados no município, com formação em nível médio, no curso de magistério. As/os coordenadoras/es ingressaram no projeto em função do interesse e envolvimento com a temática da EJA, sejam eles demonstrados no decorrer do curso de Pedagogia ou nas ações empreendidas junto aos movimentos populares, ou ainda foram convidadas para compor a equipe da coordenação por se sobressaírem como educadoras/es no Projeto AJA-Expansão. 
A prática pedagógica no Projeto AJA-Expansão realiza-se buscando: desconstruir concepções empiristas do processo de alfabetização, baseadas no ensino de letras, sílabas, palavras descontextualizadas; refletir sobre o processo de alfabetização numa abordagem sócio-interacionista, dialógica, significativa, pautada em estratégias de letramento, na realidade sociocultural dos educandos, com vistas à humanização e à formação de sujeitos leitores e escritores; perceber o tema gerador como uma metodologia de trabalho da EAJA numa perspectiva interdisciplinar de transformação da realidade; discutir sobre a importância da organização do trabalho a ser empreendido por meio do planejamento que, partindo da realidade dos sujeitos (educandas/ os e educadoras/es), possibilite o acesso à leitura e escrita da palavra e do mundo, contribuindo para entender, analisar e intervir criticamente na sociedade em que vivemos.

No encontro inicial de formação dos educadoras/es populares e nos demais que se seguem, enfatiza-se, portanto, a necessidade do planejamento das aulas, considerando a identidade lingüística e cultural das/os alunos da EAJA e a realidade em que estão inseridos - sem desenvolver um trabalho infantilizado. Além disso, o encontro inicial de formação visa trazer informações sobre o funcionamento do Projeto: estrutura e carga horária de trabalho, com ênfase na participação nos encontros semanais de formação continuada - para planejamento, troca de experiências, aprofundamento teórico - como parte da carga horária de trabalho dos educadores populares; princípios e fundamentos teórico-metodológicos que sustentam a prática pedagógica - aspectos estes que serão objeto de aprofundamento e reflexão nos encontros semanais.

A formação continuada dos educadores populares do Projeto AJAExpansão ocorre em dois momentos distintos, porém articulados entre si. São eles: o encontro semanal dos educadores populares, que se subdivide em três horários (manhã, tarde e noite) para que todos os educadores possam participar; o acompanhamento pedagógico nos núcleos de formação em que as coordenadoras atuam como observadoras e formadoras, contribuindo com orientações a partir das práticas pedagógicas observadas in loco nos grupos de alfabetização, bem como encaminhamentos, sugestôes, etc. a cada educador/a.

Para que a formação continuada empreendida seja de qualidade e tenha uma orientação comum, as coordenadoras reúnem-se semanalmente para estudo e planejamento desta, sob orientação das assessoras 
pedagógicas: professoras da UCG, UFG, além da equipe do Departamento Pedagógico da SME. O encontro semanal de formação continuada apresenta-se como um momento de reflexão coletiva da prática pedagógica, informes e estudos teóricos. Nele buscamos atender às demandas dos/as professores/as, abordando temáticas sugeridas por eles/as ou aquelas temáticas percebidas pelas coordenadoras do Projeto como necessárias de serem trabalhadas, a partir das visitas de acompanhamento pedagógico aos núcleos de alfabetização/educação de adolescentes, jovens e adultos. O encontro configura-se, também, em um espaço para trocas de experiências entre os professores do projeto.

A dinâmica dos encontros de formação vai além de trabalhos individuais e de trocas coletivas de saberes, pressupõe também a formação dos educadores populares como sujeitos em atitude investigativa, com espírito aberto, compromisso com o grupo social sob sua responsabilidade, tendo em vista a construção da prática de modo crítico, autônomo e reflexivo. Isso demanda rodadas de reflexão, planejamentos, discussões, estudos e aprofundamentos teóricos, pois educar exige renovação constante.

É um exercício permanente de reflexão e análise das práticas pedagógicas, com leituras e discussóes teóricas, como momentos inseparáveis em todo o percurso. Não se trata, portanto, de um momento de formação teórica e de aplicação prática, mas sim de um caminhar teórico-prático em que, lado a lado, num diálogo constante, buscamos observar, escutar, trocar, provocar, confrontar, construir e reconstruir permanentemente a prática, sob a luz do referencial teórico sócio-interacionista em busca da humanização.

Nesse sentido, temos vivenciado um processo de (re)orientação do fazer-pensar dos educadores que passam a compor a equipe de atuação do Projeto: ao planejar o trabalho pedagógico do dia-a-dia da sala de aula, ao definir coletiva e individualmente os rumos que se quer dar para o ensino em função do tipo de homens que se quer realmente formar, na sociedade que temos e queremos ter, trabalhando com os educandos e não para eles, ouvindo-os como parte do processo educativo dialógico.

Os encontros com os educadores são organizados com três momentos que se aproximam da proposta de planejamento/vivência a ser empreendido/a pelo/a educador/a com as/os educandas/os. O primeiro, denominado momento inicial, é quando recebemos o/a educador/a com uma mística, com textos de reflexão, fazendo a articulação do encontro 
Alfabetização de jovens e adultos: política pública e movimento popular

de formação da semana anterior com o que ora se inicia. É fundamental nesse instante criar o desejo de permanecer com o grupo, de estar ali e envolver-se no trabalho.

Os textos selecionados para o primeiro momento geralmente se referem à temática que será desenvolvida na parte central do encontro aqui, nossa intenção é proporcionar um espaço para os/as educadores/as manifestarem-se sobre o que conhecem da temática -, ou são textos para $\mathrm{o}$ ato de deliciar-se no processo de leitura, com vistas a formar educadoras/es leitoras/es e escritoras/es. A vivência deste momento inicial com o/a educador/a ocorre para que ele possa fazer parte da dinâmica da sala de aula com as/os educandas/os.

O momento central do encontro envolve as discussões teóricopráticas, tomando-se por base o processo ensino-aprendizagem desenvolvido pelas/os educadoras/es com as/os educandas/os: suas dúvidas, questionamentos, anseios, solicitações, análises, trocas de experiências com relatos e apresentações de práticas vivenciadas - as quais são discutidas teoricamente -, trabalhos em grupos, leitura e discussão de textos que subsidiem a prática pedagógica das/os educadoras/es, elaboração de atividades (planejamento) que proporcionem o avanço das/os educandas/ os, conforme os níveis de desenvolvimento que apresentam na leitura e escrita e na numerização, dentre outros.

No momento final, são dados os informes e esclarecimentos administrativos, é realizada a avaliação das atividades daquele dia e sinalizada a continuidade do trabalho do próximo encontro, bem como a entrega de materiais didático-pedagógicos. No que se refere aos encaminhamentos para a semana posterior, em geral, ficam combinadas leituras de textos, apresentação de práticas empreendidas, exposição de planos e atividades desenvolvidas durante a semana, entre outras.

Ao longo dos cinco anos de existência do Projeto AJA-Expansão temos discutido teoricamente e desenvolvido práticas pedagógicas sobre os temas: porque e como trabalhar a partir de textos; o uso de textos significativos em sala de aula - da seleção à elaboração de atividades; o tema gerador na educação popular; quem é a/o educanda/o do Projeto AJA-Expansão; é possível ler sem saber ler; portadores textuais; tipos e estruturas de textos (listas, jornal, histórias/casos, poesias, músicas, fábulas, adivinhas, parlendas, provérbios, rótulos e embalagens, carta, bilhete e cartões, textos da prática social - talão de água e luz, receita culinária e médica -, desafios, cartaz, folder/folhetos, livros literários, textos 
informativos e dissertativos); níveis de desenvolvimento da escrita; estratégias de leitura; escrita e reescrita de textos; a numerização em sala de aula; práticas de sala de aula; organização do trabalho pedagógico - planejamento e registro da aula; dentre outros.

As/os educadoras/es avaliam a formação continuada como um espaço positivo e fundamental, afirmando que ela: ajuda a pensar a organização do trabalho a ser desenvolvido em sala de aula, oferece suporte teórico-prático e ajuda a operacionalizar as idéias na prática; ajuda a superar formas tradicionais em que foram alfabetizados, saindo da prática corrente da silabação, das cópias e ditados sem sentido.

Conscientes de suas dificuldades e limitaçōes no processo de ensino-aprendizagem, as trocas de experiências são vistas como um momento de possibilidade de aprender com o outro. Muitos educadores levam para o encontro coletivo propostas de atividades desenvolvidas com êxito no seu núcleo, socializando tanto as atividades quanto os resultados obtidos. Nesses trabalhos apresentados são feitas intervençōes, buscando o aprofundamento teórico-prático, bem como uma aproximação entre as teorias estudadas e as práticas empreendidas. Fortalecemos, portanto, as "ousadias" nos processos de leitura e escrita, tomando a formação como espaço de trocas dos acertos, de apontar e discutir os equívocos, as dúvidas e construir, em conjunto, alternativas às questôes que a prática nos apresenta. Este é um momento muito esperado e valorizado pelas/os educadoras/es no processo de formação.

Pensar uma formação continuada que contribua para o/a educador/a popular alfabetizador/a aprimorar o fazer pedagógico, a partir de uma releitura da sua prática e de seus pares, com vistas à superação dos conhecimentos e fazeres, inclusive aqueles muitas vezes cristalizados, (re)elaborando e incorporando novos conceitos, tem sido um desafio que se faz presente a cada encontro, nos trabalhos de formação das/os educadoras/es populares da EJA.

É nesse contexto que são trabalhadas as dificuldades, as resistências, os desafios. Superar a soletração, os ditados e cópias sem sentido, os exercícios estruturais de fixação de fonemas, exercícios cartilhados, respostas padronizadas, textos escolhidos pela ótica e preferência do/a educador/ a, muitas vezes inadequados quanto aos interesses das/os educandas/os, são alguns desafios postos que exigem respeito e abordagem cuidadosa nos encontros de formação. 
Nesse sentido, percebemos, quer seja no momento do encontro de formação semanal - nos discursos por eles veiculados, no alheamento às atividades propostas, nos relatos de experiências e nos silêncios -, quer seja nas práticas empreendidas nos núcleos, quando alguns educadores ainda insistem em vincular-se aos métodos behavioristas de ensino-aprendizagem da lecto-escrita e numerização e resistem a abraçar de vez a proposta pedagógica do Projeto AJA-Expansão. Outros demonstram que, ora desenvolvem práticas no processo de leitura e escrita, numa abordagem sócio-interacionista, ora ainda recaem para posturas reprodutivistas. Contudo, estes e muitos outros têm tido uma abertura maior para compreensão da proposta pedagógica do Projeto, rumo à construção de uma prática que forme leitores e escritores da palavra e do mundo.

No que se refere à autoria, ainda que, ao longo da existência do Projeto AJA-Expansão, na parceria da SME com a Faculdade de Educação da UFG e UCG, tenha havido a preocupação com a sistematização dos passos trilhados nos encontros de formação, falta nesta caminhada um maior investimento dos educadores/coordenadores, não só como atores, mas como autores, na sistematização do processo percorrido, dos avanços e recuos do grupo, como forma de, ao refletir e registrar esse processo, ter a possibilidade de ir fazendo a história, podendo contá-la e divulgá-la.

Os Encontros Nacionais de Educação Jovens e Adultos (ENEJA), do MOVA-Brasil e do Fórum Goiano de Educação de Jovens e Adultos, nos quais coordenadoras/es, educadoras/es e educandas/os têm tido oportunidade de participar, vêm se constituindo em espaços privilegiados para que estes registros se concretizem, sob forma de comunicação e trocas de experiências. O esforço de todos nós, ao longo destes cinco anos, em construir e manter este espaço de intercâmbio e articulação do Projeto AJAExpansão junto aos MOVAs, com certeza, tem contribuído para o maior enraizamento da sua prática, para o aprimoramento de suas formulaçôes e realizaçōes e, certamente, para a legitimidade dos seus acúmulos.

\section{Considerações finais}

Esta experiência do Projeto AJA-Expansão vem reafirmar a possibilidade de contribuiçãoo efetiva do movimento popular na definição da política pública, neste caso específico, a política pública voltada para a educação de jovens e adultos. Não apenas na perspectiva da alfabetiza- 
ção, mas numa concepção de educação permanente de alunas/os, alfabetizadoras/es, gestoras/es, representantes da sociedade civil, instituiçôes universitárias etc., em que todos os envolvidos nesse processo, em alguma medida, se colocam frente ao desafio de aprender com ele, ressignificar suas práticas e efetivar mudanças. As mudanças vão desde a conquista do direito de voltar a estudar das/os alunas/os, à mudança de gestão da SME e das escolas, no trato com os alunos da EJA. As exigências de mudanças também se fazem no seio das outras entidades parceiras: são as associações que se integram na luta em defesa da escola; são as universidades que passam a fortalecer as discussões da EJA no âmbito do ensino, da pesquisa e da extensão.

Percebe-se, nos cinco anos de existência do Projeto, que o grupo foi construindo e reconstruindo idéias e propostas, buscando novas formas de atuação junto às/aos educadoras/es e educandas/os, com avanços significativos na prática pedagógica, tanto das/os educadoras/es, como das/os coordenadoras/es e assessoras. Uma preocupação básica é realizar, nos encontros de formação, um processo coerente com o que se deseja que seja realizado em sala de aula com as/os educandas/os.

Pressupóe-se que, nesse espaço de política pública articulada ao movimento popular, todos os participantes do Projeto constroem, numa teia constante de algumas certezas, de muitas dúvidas e de resistências, a possibilidade de acesso à educação aos jovens e adultos, imprimindo novas relações, conhecimentos, formas de linguagem e bens culturais. São mulheres e homens, sujeitos essenciais desse processo, cuja palavra, ouvida e retomada, deu inúmeros motivos para a elaboração deste texto.

\section{Recebido em outubro de 2006 e aprovado em março de 2007.}

\section{Notas}

1. Durante a gestão de Paulo Freire à frente da Secretaria Municipal de Educação de São Paulo, no governo petista de Luiza Erundina, em 1989, estabeleceu-se a parceria com movimentos populares de alfabetização de jovens e adultos, denominados a partir de então de MOVAs. Depois dessa experiência, que se configurou num modelo de política pública de educação popular, muitos MOVAs foram criados no país.

2. Em Goiânia, o atendimento à EJA é promovido de diversas formas: em parceria com a sociedade civil, por meio do Projeto AJA-Expansão, com o início do processo de alfabetização/escolarização deste segmento educativo; pelo Projeto AJA-Extensão, de $1^{\text {a à }} 4^{\mathrm{a}}$ séries, organizado por módulos e turmas multisseriadas; pelo Ensino Fundamental para Adolescentes, Jovens e Adultos, denominado de EAJA; e a EAJA Alternativa, de $5^{\text {a }}$ a $8^{\mathrm{a}}$ séries. 


\section{Referências bibliográficas}

BRANDÃO, C.R. A cultura do povo e a educação popular: 7 canções de militância pedagógica acompanhadas de enunciados de início e notas ao final. In: Bezerra, A.; Brandão, C.R. (Org.). A questão da educação popular. 2. ed. São Paulo: Brasiliense, 1980. p. 122- 135.

GOIÂNIA. Secretaria Municipal da Educação (SME). Proposta de experiência pedagógica de $1^{a}$ a $4^{a}$ séries do ensino fundamental para adolescentes, jovens e adultos (Projeto AJA). Goiânia, 1993. (mimeo).

GOIÂNIA. Secretaria Municipal da Educação (SME). Programa de atendimento a adolescentes, jovens e adultos: uma longa caminhada começa com um único passo. Goiânia: Diário Oficial; Bandeirante, 1996.

GOIÂNIA. Secretaria Municipal da Educação (SME). Projeto AJA-expansão: educação fazendo a sua parte. Goiânia, 2001. (mimeo).

PONTUAL, P. Palestra: o papel do poder público e da sociedade civil. In: ENCONTRO NACIONAL DE MOVAS, 3., 2003, Goiânia. Relatório do... Goiânia, 2003. Disponível em: <http://www.forumeja.org.br>. 